\title{
Utility of the Malayalam translation of the 7- minute screen for Alzheimer's disease risk in an Indian community
}

\author{
Celeste A. de Jager, Madhav Thambisetty ${ }^{1}$, K. V. Praveen ${ }^{2}$, P. D. Sheeba ${ }^{2}$, K. N. Ajini' ${ }^{2}$, A. Sajeev ${ }^{2}$, \\ K. K. Smitha ${ }^{2}$, L. P. Rahmathulla ${ }^{2}$, T. Ramakrishna ${ }^{3,4}$, Smith A. David \\ OPTIMA, Medical Sciences Division, University of Oxford, Oxford, ${ }^{1} M R C$ Centre for Neurodegeneration Research, Section of Old Age \\ Psychiatry, Institute of Psychiatry, King's College, London, UK, '2Department of Life Sciences, University of Calicut, Calicut, Kerala, \\ ${ }^{3}$ Department of Biotechnology, Bangalore University, ${ }^{4}$ Department of Neurology, MS Ramiah Medical College and Teaching Hospital, \\ Bangalore, Karnataka, India
}

\begin{abstract}
Background: Alzheimer's disease (AD) is suspected to be currently under-diagnosed in India, thus the need for a brief, effective screening test for the condition. Aims: We aimed to test the Malayalam translation of the 7-Minute Screen (7MS) for detecting those at high risk for $A D$ and to report on the subscores used to derive the Alzheimer's risk score. Setting and Design: This study was performed in Kerala State amongst young university students and elders in residential care homes. Materials and Methods: Two hundred and eighty-two volunteers were tested, 178 young controls (aged 20-29) and 104 literate elders, (55-92 years). None were clinically diagnosed with AD. Statistical Analyses: Elders and controls were assessed as High or Low AD Risk with the published 7MS algorithm. Performance was compared between groups with ANOVA. Results: The algorithm estimated high ( $n=61 / 104)$ or low $(n=40 / 104)$ AD risk in the elderly. Significant differences were found between controls, low- and high-risk groups on all four components of the screen (Orientation: $F=131.1$, Enhanced Cued Recall: $F=23.4$, Clock Drawing: $\mathrm{F}=65.1$, Verbal Fluency: $\mathrm{F}=15.7, P<0.0001$ for all) and in the risk scores $(F=144.7, P<0.0001)$. Age and gender affected verbal fluency, orientation and clock drawing performance. The high-risk group had worse scores for orientation and better scores for memory than previously reported for $A D$ cases in other populations. Conclusions: The 7MS may be a useful screening test for cognitive impairment in India. Suggestions are given for revising the 'risk algorithm' for more appropriate AD risk assessment in this population.
\end{abstract}

Key words: Alzheimer's disease, cognitive impairment, elderly, memory

Screening for Alzheimer's disease (AD) is not a routine diagnostic procedure for the elderly in India and it is likely that dementia is vastly under-diagnosed. Poor awareness of dementia in the community is a factor that influences the number of older people seeking medical attention. The World Health Organization (WHO) estimates that by the year 2020, 70\% of the world's population aged 60 years and above will live in developing countries, with $14.2 \%$ located in the Indian subcontinent. ${ }^{[1]}$ Furthermore, out of the 114 million estimated to have dementia worldwide by the year 2050, some $75 \%$ will be in less developed countries. ${ }^{[2]}$

There has been good validation of a one-stage procedure for dementia diagnosis in developing countries by the 10/66 group. ${ }^{[3]}$ However, this procedure has a long administration time complemented by an informant interview. The Malayalam version of the Addenbrooke's Cognitive Examination (ACE) has been used in early detection of dementia in India. ${ }^{[4]}$ This battery is lengthy with nine component tests. The Mini Mental Status Examination (MMSE) has been translated into Hindi ${ }^{[5]}$ and Malayalam. However, it is biased by age and education level. ${ }^{[4,6,7]}$ Appropriate cut-off scores can improve the sensitivity of culturally modified versions of the MMSE. ${ }^{[8,9]}$

Further research into briefer, effective, culture-fair screening tests for those at risk for $\mathrm{AD}$ is needed to highlight the need for detailed diagnostic evaluation of those with deficits beyond that expected with normal ageing. We report the initial testing of a translated version of such a screening tool, the 7-Minute Screen (7MS), for acceptability and utility in Calicut, India via a collaborative study with the University of Oxford, UK.

The $7 \mathrm{MS}^{[10]}$ is an inexpensive screening tool for early to advanced $\mathrm{AD}$, readily translatable for crosscultural use. ${ }^{[11-13]}$ It has better sensitivity to AD than the MMSE, with no age or education bias. ${ }^{[13,14]}$ A primary care practice reported excellent positive and negative predictive value of the $7 \mathrm{MS},{ }^{[9]}$ while a recent study in the Netherlands showed lower sensitivity for other types of dementia and for depression. ${ }^{[13]}$ Its usefulness and tolerability for large-scale community memory 
screening has also been reported. ${ }^{[15]}$

Our aims in the present study were to test the suitability of the 7MS for detection of cognitive impairment in an Indian community sample by comparing the performance of older participants with those of young controls and with similar studies in other countries. We also wished to examine the contribution of the separate subscores of the translated 7MS to the risk algorithm.

\section{Materials and Methods}

This study was approved by the local Institutional Ethics Committee of the University of Calicut. Between April 2002 and June 2002, 282 volunteers from Calicut city and Malappuram district in Kerala State were tested with the 7MS (translated into Malayalam) after obtaining signed informed consent and with the assistance of the patient caregiver if appropriate. Volunteers included 178 young healthy controls (mean age 23, range, 20-29; 90 males, 88 females) all of whom were graduate or postgraduate students at the University of Calicut and 104 older participants with a mean age of 68, range, 55-92 (40 males, 64 females). Ninety older volunteers were recruited from four different old age homes in and around Calicut city. We hypothesized that the likelihood of identifying participants with cognitive impairment in this population would be higher than that in the general community. The other 14 elders were recruited from Thenhipalam panchayat. Subjects who had suffered a major stroke in the previous two years were excluded. Only literate older volunteers were included; 87 were educated above the fifth grade including four graduates, while 17 had no formal education. Subjects had not been previously assessed for dementia status and did not undergo a formal clinical assessment during screening with the 7MS. The accuracy of the translation was tested with the young volunteers as a back translation was not done.

The 7MS was administered to volunteers by six graduate students from the University of Calicut. The 7MS subtests were combined into a booklet with full instructions for administration and scoring. Little further training and expertise in psychometric testing was therefore required of the testers. A calculator was also provided for computing the $\mathrm{AD}$ risk score from the algorithm published by Solomon et al. ${ }^{[10]}$ The four subtests of the 7MS included: (i) Benton's temporal orientation test (BTO) comprising five questions about the current date and time, ${ }^{[16]}$ (ii) visual Buschke selective reminding test with enhanced cued recall (ECR), ${ }^{[17]}$ comprising 16 items with 16 different category cues displayed on four cards. After naming the items on each card, the card is turned over and the subject asked to recall each item. The recall can be repeated up to three times to ensure that all the items have been registered or encoded. After a non-verbal interference test (clock drawing), the subject is asked to recall all 16 items. Category cues are given to aid recall of items not retrieved by free recall. The free and cued recall scores are summed for the total recall score. (iii) Clock drawing task (CDT); ${ }^{[18]}$ the subject is told to draw a clock with all the numbers in it, and to set the hands at 20 min before four o' clock, and (iv) verbal category fluency task (VFT) ${ }^{[19]}$ for animals named in one minute. All of these tests have been previously reported to be sensitive to $\mathrm{AD} \cdot{ }^{[20-27]}$

\section{Statistical analyses}

Age and raw scores on the four components of the 7MS were compared between low- and high-risk groups using General Linear Model analysis of variance and post-hoc Games-Howell tests for non-parametric data. Sex ratios were determined by Chi-square analysis. Effects of age and gender on task performance were also determined by ANOVA with General Linear Model analysis (using the Statistical Package for the Social Sciences 11.0 (SPSS for Windows) software. P-values of $<0.001$ were considered significant. Raw scores on the 7MS were converted to probability scores for dementia according to the algorithm produced by Solomon et al., ${ }^{[26]}$ based on a logistic regression model. The algorithm for estimating probability or 'risk' for $\mathrm{AD}$ is as follows:

$\log (\mathrm{P} / 1-\mathrm{P})=35.59-1.303 \mathrm{ECR}-1.378 \mathrm{VFT}+3.298$ OT -0.838 CDT.

The probability of $\mathrm{AD}$ or dementia increases with a higher total score. A negative score is indicative of low risk. Three subjects were excluded from these analyses as their probability scores were between the low- and high-risk cutoffs and they were classified as needing retesting. Receiver Operating Characteristic (ROC) curve analysis was performed to show the discrimination of the risk score and subscores for the groups (high and low risk). The analysis determines the sensitivity of the tests to high risk (true positives) and the specificity (true negatives) for the control state (low-risk) at the optimum cutoff point on each test. Overall discrimination is estimated by the area under the curve.

\section{Results}

Demographic data on the test subjects are presented in Table 1. There was a significant difference in age between low- and high-risk older subjects $(\mathrm{F}=4.19$, $P<0.03)$. The gender ratio $\left(\chi^{2}=20.71, P<0.0001\right)$ was different between the three groups (young control, low- and high-risk elderly) with a higher ratio of females $(77 \%)$ in the high-risk group.

Significant differences were found between the young controls, low- and high-risk elderly on all four components of the 7MS [Table 1]. Post-hoc GamesHowell tests showed no difference between young controls and low-risk older adults in orientation and 
Table 1: Demographics of the study population and performance on $7 \mathrm{MS}$ tasks shown as mean, SD and (95\% Confidence Intervals) between young controls, low-risk and high-risk older participants compared using ANOVA by General Linear Model (GLM) with age and sex entered as covariates

\begin{tabular}{|c|c|c|c|c|c|}
\hline Test & df & $\begin{array}{l}\text { Young controls } \\
(n=178)\end{array}$ & $\begin{array}{c}\text { Low-risk older } \\
\text { participants }(n=40)\end{array}$ & $\begin{array}{c}\text { High-risk older } \\
\text { participants }(n=61)\end{array}$ & $F$-ratio, $P$-value \\
\hline Age & & $23.2(2.1)$ & $65.4(9.4)$ & $69.2(11.5)$ & $\begin{array}{c}F=1483.9, P<0.0001 \\
(F=4.19, P<0.03)^{*}\end{array}$ \\
\hline Gender $(\% F)$ & & $49 \%(n=87)$ & $48 \%(n=19)$ & $77 \%(n=47)$ & $F=20.71, P<0.0001$ \\
\hline BTO $(0-113)$ & 2 & $\begin{array}{c}0.26,0.63 \\
(\mathrm{Cl} 0.17-0.34)\end{array}$ & $\begin{array}{c}0.5,0.85 \\
(\mathrm{Cl} 0.23-0.77)\end{array}$ & $\begin{array}{c}60.1,38.03 \\
(\mathrm{Cl} 49.5-69.2)\end{array}$ & $F=131.1, P<0.0001$ \\
\hline Cued recall $(0-16)$ & 2 & $\begin{array}{c}15.89,0.38 \\
\text { (Cl } 15.85-15.95)\end{array}$ & $\begin{array}{c}15.7,0.56 \\
(\mathrm{Cl} 15.52-15.88)\end{array}$ & $\begin{array}{c}13.98,2.43 \\
(\mathrm{Cl} 13.36-14.61)\end{array}$ & $F=23.4, P<0.0001$ \\
\hline Verbal fluency & 2 & $\begin{array}{c}32.87,9.54 \\
(\mathrm{Cl} 31.46-34.28)\end{array}$ & $\begin{array}{c}20.03,5.68 \\
(\mathrm{Cl} 18.21-21.84)\end{array}$ & $\begin{array}{c}11.25,5.55 \\
(\mathrm{Cl} 9.83-12.67)\end{array}$ & $F=15.7, P<0.0001$ \\
\hline Clock drawing (0-7) & 2 & $\begin{array}{c}6.33,0.76 \\
(\mathrm{Cl} 6.22-6.44)\end{array}$ & $\begin{array}{c}5.50,1.55 \\
(\text { CI } 5.00-5.99)\end{array}$ & $\begin{array}{l}3.15,1.83 \\
(2.68-3.62)\end{array}$ & $F=65.1, P<0.0001$ \\
\hline Probability score & 2 & $\begin{array}{c}-34.86,13.7 \\
(\mathrm{Cl}-26.88-32.83)\end{array}$ & $\begin{array}{c}-15.42,12.19 \\
(\mathrm{Cl}-18.13-12.71)\end{array}$ & $\begin{array}{c}197.49,127.66 \\
(\mathrm{Cl} 164.8-230.2)\end{array}$ & $F=144.7, P<0.0001$ \\
\hline
\end{tabular}

BTO, Benton's temporal orientation, *Comparison between low and high-risk participants only

memory performance, while young controls and high risk older adults showed significant differences in performance on all tests, as did low-risk older adults vs. high-risk older adults.

General Linear Model (ANOVA) comparing effects of age and gender on performance of subtests between the young, low- and high-risk groups revealed a main effect of age $(F=6.54, P=0.0001)$ but not of gender. Multivariate analyses showed that poorer performance with increased age was significant for one subtest, namely, verbal category fluency $(F=6.75, P=0.002)$. Males had better performance than females in orientation $(F=12.6, P=0.001)$. When young controls were excluded from the analysis, group-by-gender interactions were significant for orientation and clock drawing $(F=3.3, P=0.04)$.

\section{Receiver operating characteristic \\ Curve analysis}

In order to compare how the subtests of the 7MS contributed to the risk score, ROC curve analysis was performed in a similar manner to that by Robert et al., with a shortened version of the 7MS. ${ }^{[28]}$ The risk score algorithm defined the high- and low-risk groups and therefore had perfect discrimination $(100 \%$ area under the curve). The orientation test score showed 98\% discrimination between the groups. Thus, the orientation score had a very high weighting towards the risk score. Clock drawing and verbal fluency tests had $86 \%$ and $88 \%$ discrimination between groups respectively. The memory test had the lowest discrimination between the groups (76\%), with 95\% specificity for low risk and only $48 \%$ sensitivity to high risk. Only 29 of the 61 high-risk subjects scored below the cutoff for cognitive impairment on this test (1.5SD below the low-risk group mean). Thus the remaining 32 high-risk subjects had normal memory, and were probably incorrectly assigned as high-risk due to their orientation score. [Figure 1, Table 2].

\section{Comparison with other studies}

In Table 1 the elderly subjects were divided into two groups, high and low risk, whereas in Table 3, the elders were combined into one group of communityscreened elders for comparison with the New England community-screened cohort. Low-risk older participants in our study [Table 1] performed similarly

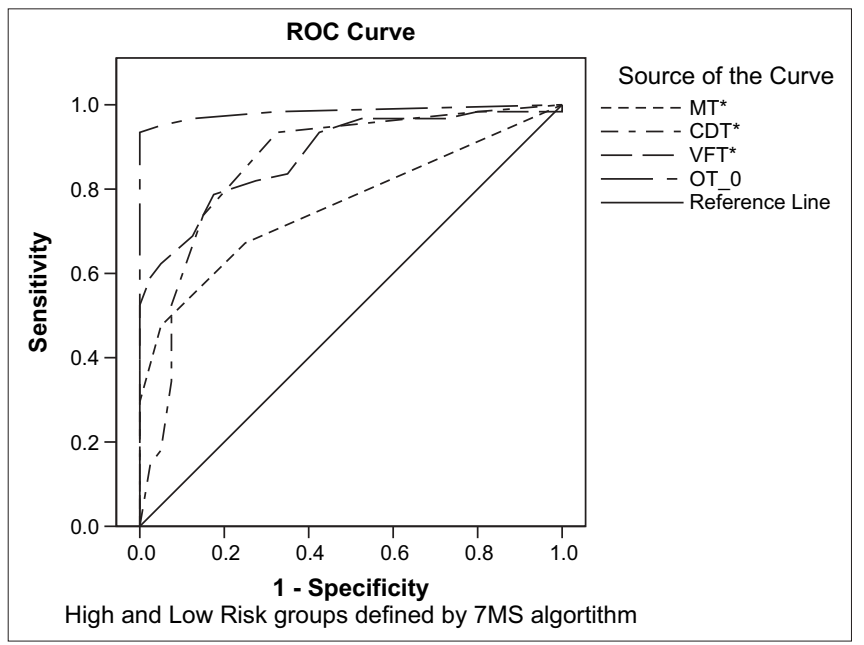

Figure 1: Receiver Operating Characteristic curves for sensitivity and specificity between high- and low-risk elders for all the subtests of the 7MS. Abbr. MT, memory test; CDT, clock drawing task; VFT, verbal fluency; OT, orientation

\begin{tabular}{|c|c|c|c|c|}
\hline Test & $\begin{array}{l}\text { Area under } \\
\text { curve }\end{array}$ & Sensitivity & Specificity & $\begin{array}{l}\text { Cutoff } \\
\text { score }\end{array}$ \\
\hline MT & 0.76 & 0.48 & 0.95 & 14.5 \\
\hline CDT & 0.86 & 0.74 & 0.85 & 4.5 \\
\hline VFT & 0.88 & 0.79 & 0.83 & 14.5 \\
\hline OT & 0.98 & 0.95 & 0.95 & 2.5 \\
\hline
\end{tabular}




\begin{tabular}{|c|c|c|c|c|}
\hline & USA $^{[10]}$ & New England ${ }^{[14]}$ & Kerala, India & USA $^{[10]}$ \\
\hline $7 \mathrm{MS}(\mathrm{n})$ & Control $(n=60)$ & Community $(n=599)$ & Elders $(n=104)$ & AD patients $(n=60)$ \\
\hline Age (range or SD) & $77.5(66-91)$ & $71.4 \pm 9.5$ & $67.8 \pm 10$ & (66-89) 77.6 \\
\hline$\% \mathrm{~F}^{*}$ & $46 \%$ & $68 \%$ & $61.5 \%$ & $50 \%$ \\
\hline MMSE & $28.7(2.1)$ & & & $21(7.8)$ \\
\hline BTO* & $0.4(0.1)$ & $2.4 \pm 9.6$ & $35.5 \pm 41.3$ & $37.9(4.2)$ \\
\hline Cued recall & $15.9(0.4)$ & $14.9 \pm 2.1$ & $14.7 \pm 2.1$ & $6.8(0.7)$ \\
\hline Fluency & $19.0(0.7)$ & $16.3 \pm 5.4$ & $14.7 \pm 7.0$ & $8.8(0.5)$ \\
\hline Clock drawing & $6.3(0.1)$ & $6.1 \pm 1.4$ & $4.1 \pm 2.1$ & $3.2(0.3)$ \\
\hline
\end{tabular}

BTO, Benton's temporal orientation; AD, Alzheimer's disease; \%F, \%female

to those in the original US study [Table 3] and other studies $^{[11-13]}$ in orientation (0.5 \pm 0.85 vs. $0.4 \pm 0.1$ ), memory ( $15.7 \pm 0.6$ vs. $15.9 \pm 0.4)$ and verbal fluency $(20.0 \pm 5.6$ vs. $19.0 \pm 0.7)$, but had lower scores on clock drawing ( $5.5 \pm 1.6$ vs. $6.3 \pm 0.1$ ). Our high-risk older participants [Table 1] scored much worse in orientation $(60.1 \pm 38.0$ vs. $37.9 \pm 4.2)$ than $\mathrm{AD}$ patients in the Solomon ${ }^{[10]}$ and other studies ${ }^{[11-13]}$ better in memory (13.98 \pm 2.4 vs. $6.8 \pm 0.7)$ and verbal fluency $(11.25 \pm 5.6$ vs. $8.8 \pm 0.5)$ and equivalent in clock drawing ( $3.15 \pm 1.8$ vs. $3.2 \pm 0.3)$. In comparison with the community screening study, ${ }^{[14]}$ scores for our elderly group as a whole [Table 3] were poorer in orientation, clock drawing and fluency, but there was no difference in the memory scores $(14.9 \pm 2.1$ vs. $14.7 \pm 2.07)$.

\section{Discussion}

The Malayalam 7MS was well understood by young healthy controls who performed similarly to healthy elderly controls in other studies in orientation and cued recall, and better in verbal fluency and clock drawing. Low-risk older adults had scores similar to elderly controls in other studies. This confirms the accuracy of the Malayalam translation compared with the original English version. Low- and high- risk older adults showed significant differences in all subscores which suggests that the test is sensitive to cognitive impairment typical of AD. Verbal fluency and clock drawing were age-sensitive while orientation was poorer for women. Memory performance was not associated with age or gender.

The main finding of our study was that the 7MS risk algorithm gave an overly high probability (58.7\%) for $\mathrm{AD}$ in comparison with the New England community screening study, with only $16.7 \%$ of individuals identified as at high-risk. ${ }^{[15]}$ In addition, performance of the high-risk group in the Benton's orientation test was worse than any reported so far, although scores for young controls and low-risk older participants are within previously reported ranges. ${ }^{[10,11-13,26,28,29]}$ This suggests an overriding weighting of this subtest on the outcome of the screen as was shown by the ROC analysis. Orientation questions have been successfully used in a Sinhalese translation of the MMSE with no extra weighting. ${ }^{[30]}$

The memory test showed good specificity for low-risk but poor sensitivity to high-risk subjects. Episodic memory impairment is one of the earliest and most common symptoms of early AD. Thus its inclusion in a dementia screen should enhance the sensitivity of the screen. ${ }^{[27]}$

These findings suggest that many of those identified as 'high risk' do not have the typical cognitive profile of Alzheimer's disease. This group may have a multi-factorial etiology including $\mathrm{AD}$, other dementias, depression, and other medical conditions such as vitamin B12 deficiency or hypothyroidism. Alternatively, they may have been unable to answer the orientation questions. Cues that facilitate orientation to time were likely to be limited for old-age home residents in the present study, with limited access to television, radio or newspapers and little interaction with family members. Regular observance of important occasions like anniversaries of birth/death in the family and celebration of religious festivals is not possible in these circumstances.

Category fluency mean scores for the low and highrisk groups were both similar to previously published results. However, there may have been an effect of low education level on performance as shown by Ratcliff et al., ${ }^{[31]}$ with a fluency task. The clock drawing performance of the low-risk group was poorer than that of other community elders, ${ }^{[14]}$ suggesting that clock drawing may not be an appropriate test in India for those with low levels of formal education or from rural communities.

Overall, our results suggest that in an undiagnosed community sample in this region of India accurate detection of $\mathrm{AD}$ risk is less achievable than hypothesized from previous reports of good sensitivity and specificity of the 7MS. The limitations of this study are that oldage residents are not likely to be representative of the wider community in terms of health and functional ability, and where a high proportion of volunteers may have been disoriented. No clinical assessment for $A D$ with accepted criteria such as NINCDS-ADRDA had been applied, nor had severity of cognitive impairment been assessed with a scale such as the Clinical Dementia 
Rating scale. Thus the sensitivity of the 7MS for AD could not be reliably and accurately assessed. Moreover, effects of education could not be determined. As the young control group comprised university students with high levels of formal education, their performance compared to low-risk elders had limited use. Studies in India with the Malayalam $\mathrm{ACE}^{[32]}$ and a dementia assessment scale ${ }^{[33]}$ showed significant effects of education level on test performance.

The 7MS screen may be useful with certain modifications in developing countries. Further work in this collaborative study could include validation of the screen in a more representative elderly community sample compared with a group of clinically diagnosed $\mathrm{AD}$ patients. Education level adjustments might also increase its sensitivity. The orientation subscore should be given lower weighting or questions could be altered to be more culturally appropriate. Benefits of the 7MS are its brevity and tolerability by the elderly, ease of administration by trained non-professionals, and its specific focus on the cognitive deficits associated with $\mathrm{AD}$. The 7MS translated well into Malayalam and gave comparable scores to other studies for low-risk elders. With some simple modifications, this inexpensive instrument may be of enormous use for cognitive screening in India and could highlight the need for further diagnostic assessment of at-risk subjects. Once the modified screen is validated, it could be used in clinical studies to explore associations of cognition with underlying $\mathrm{AD}$ pathology.

\section{Acknowledgments}

TR thanks Exeter College, University of Oxford for the award of a Senior Visiting Fellowship in 2001. This allowed the initiation of the current collaboration with Professor AD Smith and OPTIMA. He is grateful to Prof. Dr MS Thimmappa, Vice chancellor, and Prof. Dr Geethabali, Coordinator, Biotechnology, Bangalore University, for the award of a visiting professorship. Madhav Thambisetty holds a research fellowship from the Alzheimer's Society and is an Emanoel Lee medical research fellow at St. Cross College, Oxford. We would like to express our gratitude to all the volunteers who participated in the study.

\section{References}

1. Population ageing: A looming public health challenge. Health Millions $1998 ; 24: 20-2$

2. Wimo A, Winblad B, Aguero-Torres H, von Strauss E. The magnitude of dementia occurrence in the world. Alzheimer Dis Assoc Disord 2003;17:63-7.

3. Prince M, Graham N, Brodaty H, Rimmer E, Varghese M, Chiu H, \&al. Alzheimer Disease International's 10/66 Dementia Research Group one model for action research in developing countries. Int J Geriatr Psychiatry 2004;19:178-81.

4. Mathuranath PS, Hodges JR, Mathew R, Cherian PJ, George A, Bak TH. Adaptation of the ACE for a Malayalam speaking population in southern India. Int J Geriatr Psychiatry 2004;19:1188-94.
5. Ganguli M, Dube S, Johnston JM, Pandav R, Chandra V, Dodge HH. Depressive symptoms, cognitive impairment and functional impairment in a rural elderly population in India: A Hindi version of the geriatric depression scale (GDS-H). Int J Geriatr Psychiatry 1999;14: $807-20$.

6. Mungas D, Marshall SC, Weldon M, Haan M, Reed BR. Age and education correction of Mini-Mental State Examination for English and Spanish-speaking elderly. Neurology 1996;46:700-6.

7. Murden RA, McRae TD, Kaner S, Bucknam ME. Mini-Mental State exam scores vary with education in blacks and whites. J Am Geriatr Soc 1991;39:149-55

8. Rait G, Morley M, Burns A, Baldwin R, Chew-Graham C, St Leger AS. Screening for cognitive impairment in older African-Caribbeans. Psychol Med 2000;30:957-63.

9. Rakusa M, Granda G, Kogoj A, Mlakar J, Vodusek DB. Mini-Mental State Examination: Standardization and validation for the elderly Slovenian population. Eur J Neurol 2006;13:141-5.

10. Solomon PR, Hirschoff A, Kelly B, Relin M, Brush M, DeVeaux RD, \& al. A 7 minute neurocognitive screening battery highly sensitive to Alzheimer's disease. Arch Neurol 1998;55:349-55.

11. Tsolaki M, Iakovidou V, Papadopoulou E, Aminta M, Nakopoulou E, Pantazi T, $₫$ al. Greek validation of the seven-minute screening battery for Alzheimer's disease in the elderly. Am J Alzheimers Dis Other Demen $2002 ; 17: 139-48$.

12. Kálmán J, Boda K, Bende Z, Janka Z. Screening for dementia syndromes: The Hungarian experience with the 7-Minute-Test. Orv Hetil 2003;144:1929-38.

13. Meulen EF, Schmand B, van Campen JP, de Koning SJ, Ponds RW, Scheltens P, \& al. The seven minute screen: A neurocognitive screening test highly sensitive to various types of dementia. J Neurol Neurosurg Psychiatry 2004;75:700-5.

14. Lawrence J, Davidoff D, Katt-Lloyd D, Auerbach M, Hennen J. A pilot program of improved methods for community-based screening for dementia. Am J Geriatr Psychiatry 2001;9:205-11.

15. Lawrence JM, Davidoff DA, Katt-Lloyd D, Connell A, Berlow YA, Savoie JA. Is large-scale community memory screening feasible? Experience from a regional memory-screening day. J Am Geriatr Soc 2003;51:1072-8.

16. Benton AL. Contributions to neuropsychological assessment. New York: Oxford University Press; 1983.

17. Grober E, Buschke H, Crystal H, Bang S, Dresner R. Screening for dementia by memory testing. Neurology 1988;38:900-3.

18. Wolf-Klein GP, Silverstone FA, Levy AP, Brod MS. Screening for Alzheimer's disease by clock drawing. J Am Geriatr Soc 1989;37:730-4.

19. Monsch AU, Bondi MW, Butters N, Salmon DP, Katzman R, Thal L.J. Comparisons of verbal fluency tasks in the detection of dementia of the Alzheimer type. Arch Neurol 1992;49:1253-8.

20. Brodaty H, Moore CM. The Clock Drawing Test for dementia of the Alzheimer's type: A comparison of three scoring methods in a memory disorders clinic. Int J Geriatr Psychiatry 1997;12:619-27.

21. Lin KN, Wang PN, Chen C, Chiu YH, Kuo CC, Chuang YY, \& al. The three-item clock-drawing test: A simplified screening test for Alzheimer's disease. Eur Neurol 2003;49:53-8.

22. Knopman DS, Ryberg S. A verbal memory test with high predictive accuracy for dementia of the Alzheimer type. Arch Neurol 1989;46:141-5.

23. Henry JD, Crawford JR, Phillips LH. Verbal fluency performance in dementia of the Alzheimer's type: A meta-analysis. Neuropsychologia 2004;42:1212-22.

24. Grober E, Kawas C. Learning and retention in preclinical and early Alzheimer's disease. Psychol Aging 1997;12:183-8.

25. Vogel A, Mortensen EL, Gade A, Waldemar G. The Category Cued Recall test in very mild Alzheimer's disease: Discriminative validity and correlation with semantic memory functions. Eur J Neurol 2007;14:102-8.

26. Solomon PR, Pendlebury WW. Recognition of Alzheimer's disease: The 7 Minute Screen. Fam Med 1998;30:265-71.

27. Ivanoiu A, Adam S, Van der Linden M, Salmon E, Juillerat AC, Mulligan

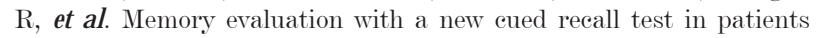
with mild cognitive impairment and Alzheimer's disease. J Neurol 
$2005 ; 252: 47-55$.

28. Robert PH, Schuck S, Dubois B, Olié JP, Lépine JP, Gallarda T, đ al. Screening for Alzheimer's disease with the short cognitive evaluation battery. Dement Geriatr Cogn Disord 2003;15:92-8.

29. Solomon PR, Brush M, Calvo V, Adams F, DeVeaux RD, Pendlebury WW, e al. Identifying dementia in the primary-care practice. Int Psychogeriatr 2000b;12:483-93.

30. de Silva HA, Gunatilake SB. Mini Mental State Examination in Sinhalese: A sensitive test to screen for dementia in Sri Lanka. Int J Geriatr Psychiatry 2002;17:134-9.

31. Ratcliff G, Ganguli M, Chandra V, Sharma S, Belle S, Seaberg E, \& al. Effects of literacy and education on measures of word fluency. Brain
Lang 1998;61:115-22.

32. Mathuranath PS, Cherian JP, Mathew R, George A, Alexander A, Sarma SP. Mini Mental State Examination and the Addenbrooke's Cognitive Examination: Effect of education and norms for a multicultural population. Neurol India 2007;55:106-10.

33. Iype T, Ajitha BK, Antony P, Ajeeth NB, Job S, Shaji KS. Usefulness of the Rowland Universal Dementia Assessment scale in South India. J Neurol Neurosurg Psychiatry 2006;77:513-4.

Accepted on 12-03-2008

Source of Support: Nil, Conflict of Interest: None declared.

\section{Author Help: Sending a revised article}

1) Include the referees' remarks and point to point clarification to those remarks at the beginning in the revised article file itself. In addition, mark the changes as underlined or coloured text in the article. Please include in a single file

a. referees' comments

b. point to point clarifications on the comments

c. revised article with text highlighting the changes done

2) Include the original comments of the review ers/editor w ith point to point reply at the beginning of the article in the 'Article File'. To ensure that the reviewer can assess the revised paper in timely fashion, please reply to the comments of the referees/editors in the follow ing manner.

- There is no data on follow-up of these patients.

Authors' Reply: The follow up of patients have been included in the results section [Page 3, para 2]

- $\quad$ Authors should highlight the relation of complication to duration of diabetes.

Authors' Reply: The complications as seen in our study group has been included in the results section [Page 4, Table] 